\title{
DEVELOPMENT OF PSYCHOLOGICAL STRUCTURE PROFESSIONAL LAWYER'S SELF-CONSCIOUSNESS IN THE CONDITIONS OF HIGHER EDUCATION
}

\author{
Mikhail Demidov ${ }^{1}$, Mikhail Smirnov $^{2 \star}$, Polina Starygina ${ }^{3}$, Olga Yakhina ${ }^{4}$ \\ ${ }^{1}$ Russian University of Cooperation, Cheboksary, Russian Federation, mvdemidov@yandex.ru \\ ${ }^{2}$ Mari State University, Yoshkar-Ola, Russian Federation, micsha.smi2015@yandex.ru \\ ${ }^{3}$ Mari State University, Yoshkar-Ola, Russian Federation,poly222@yandex.ru \\ ${ }^{4}$ Mari State University, Yoshkar-Ola, Russian Federation, olgeens@mail.ru \\ ${ }^{*}$ Corresponding Author
}

\begin{abstract}
The most important problem of education is developing professional self-consciousness of future legal specialists. It is determined by the necessity of rapid adaptation to modern dynamic life and conditions of practical activity. The vast array of current legislation, its frequent changes, gaps and conflicts require lawyers to have a high level of theoretical knowledge and law enforcement practice. However practice shows wick relationship between universities and the sphere of graduates activity. After graduation young specialists do not know how to use the knowledge of various branches of law received in the university.

Modern conditions can be characterized by the instability of the socio-economic environment. As usual training and selection of lawyers is based on the assessment of a number of psychological qualities, as well as professional competence, including theoretical and practical training. However, these indicators are not an accurate basis for predicting and achieving a high level of professional activity productivity.
\end{abstract}

Keywords: professional self-consciousness, psychological structure of the individual, professional adaptation, psychological skills and abilities, university training

\section{INTRODUCTION}

The importance of lawyer's self- consciousness developing is determined by the necessity for rapid adaptation to modern dynamic life and conditions of practical activity. The vast array of current legislation, its frequent changes, gaps and conflicts require lawyers to have a high level of knowledge of theory and law enforcement practice. However relationship between universities and the sphere of graduates' activity are not always robust. The adaptation to independent professional work takes a lot of time. In this regard the issue of finding new ways and methods of teaching that can form psychological skills of practical use of constantly changing legislation becomes particularly relevant in modern conditions. Such skills can help to reduce to a minimum or eliminate the adaptation time for future lawyers to their chosen profession. 
We have obtained data showing that a lot of the beginning legal professionals face to serious difficulties associated not only with a lack of professional experience, but also with insufficient psychological training to solve a number of communication, emotional, cognitive problems, as well as problems associated with a high level of moral and volitional tension in legal work. These conclusions are confirmed by the results of surveys. Surveys were conducted among students, practice managers and officials who are responsible for initial professional training of employees in law enforcement agencies.

\section{PURPOSE}

The resolution of described contradiction is impossible without work directed on incensement of the future lawyer's professional self- consciousness. Moreover, this activity should have at least two directions: the formation of knowledge and skills necessary for young professionals in changing socio-economic relations, and on the other hand, the development of professionally important personal qualities that allow a young specialist to adapt to the professional activity and to join the labour activity with the greatest benefit for their personal development. However adaptation to the conditions of work in specific places is based on the main amount of knowledge and skills acquired at the university. In this sphere the presence of a young specialist's professional self- consciousness plays not only important but the main role. Self- consciousness in this context can be defined as "how well the student imagines the specific content of their chosen type of legal work and how well they diagnose the presence or absence of the necessary qualities" [1].

\section{MATERIALS AND METHODS}

The problem of consciousness and self-consciousness is examined by representatives of various sciences such as philosophy, sociology, psychology, pedagogy and psychiatry. In philosophical terms, consciousness is a subjective form of human life activity in contrast to its objective content (its material conditions, objects and means), i.e., being.

The physiological nature of consciousness was developed by Russian researchers and reflected in the works of V. M. Bekhterev, I. M. Sechenov, I. P. Pavlov, A. A. Ukhtomsky, and others. The question of the material foundations of consciousness is solved rather as a question of a special, motion of matter higher form at present $[2,3]$.

In psychological terms the study of individual consciousness implies its representation as a multi-level system that includes both conscious and unconscious components. Many important categories are associated with the concept of consciousness in psychology: personality, activity, communication, subject, etc. According to V. A. Brushlinsky, consciousness is especially important for a person because subject of activity forms and develops goals during reflection, i.e. the goals of activity, communication, contemplation and other types of activity [4].

The dialectic of the external and internal is very important in the process of consciousness. According to V. A. Barabanshchikov the individual is not separate and does not oppose the perceived world as it seems to ordinary consciousness. A person is immersed in this world from birth and individual is a necessary condition for global existence and development. A person modifies the world, acts practically, transforms it according to own needs, goals and values, turns it into a personal asset-the inner world [5].

The structure of consciousness has a complex structure: the knowledge is its core. Knowledge is acquired by a person in the process of cognitive activity and it exists in the form of sensations, representations, concepts and theoretical constructs.

Consciousness and psyche are interrelated, but are not identical. E. V. Shorokhova points to a specific characteristic of consciousness, which is the main quality of consciousness as a special form of mental reflection - meaningfulness. Consciousness is not a combination of mental processes and is not reduced to any of them. It is not a "superstructure" over the psyche, but it is carried out through mental processes, the main place among which is occupied by thinking [6].

Consciousness is intimately connected with activity. Their interaction is found in both ontogeny and phylogeny of human development. The principle of consciousness and activity unity is important. According to A. N. Leontiev human activity determines the formation of consciousness. Consciousness improves adaptation to the external world by regulating human activity [7]. Consciousness forms the internal plan of activity, its program. Dynamic models of reality are synthesized in consciousness. Such models guide a person in the surrounding physical and social environment.

The unity of consciousness and activity are pointed by R. V. Gabdreev. A person learned to understand, to control, to aware himself by interacting with the world around. Consciousness arises, develops and 
manifests itself in the process of activity.

A. N. Leontiev consistently revealed the essence of consciousness from the position of activity theory. He refuted the possibility of identifying consciousness with the combination of mental processes (thinking, perception and memory), skills and emotional experiences. Consciousness must be psychologically revealed in its own characteristic. It must be understood not only as knowledge, but also as attitude, as direction.

On the other hand, as V. N. Myasishchev notes a person's actions and experiences are determined not by direct external influences, but by their accumulated generalization in the inner world. The inner world in its turn represents the system of human relations which determine the mediated nature of reactions to the effects of the surrounding world and his external initiative and independent behavior [8].

\section{RESULTS AND DISCUSSION}

A person forms his inner world by assimilating and internalizing historically forms of social activity. The integral, concentrated expression of someone's inner world is self-consciousness.

Numerous approaches and theoretical findings have led to the construction of complex procedural models of self-consciousness, which can be represented in a certain perspective by three lines. The first line comes from Freud, who in his early works tried to explain the dynamics of hidden needs, thereby laying the logic of self-consciousness research in the framework of personality theory. The second line originates in the works of James who traced the phenomenon of consciousness and self-consciousness in volitional acts. The third direction was implemented in Russian psychology and was based on the Marxist postulate that human consciousness is a realized being. The essence of this approach was the position of A. N. Leontiev that "the essence of the 'I' lies outside the consciousness of a person and is in his being" [7].

Analysis of researches in the field of self-consciousness shows that this phenomenon is understood as a specific feature of the personality which determines individual differences in the nature of a person's location in the surrounding world, a person's ideas about himself, individual characteristics, intentions, attitudes, etc.

A. G. Spirkin identifies self-control and self-knowledge as the leading functions of self-consciousness. The first function is focused on the knowledge of the external world. The second is directed on the knowledge of oneself. At the same time, self-control is a necessary condition and tool for adequate behavior and activity. It is based on independence and objectivity of thoughts and activities. Self-knowledge clarifies the meaning of activity, because it is a powerful factor of self-improvement.

At the same time there is another point of view. It sets that self-consciousness is a characteristic and indicator of a higher level of mental life than object consciousness. Self-consciousness is formed in later periods of the process of personal development, it is the result of the formation and development of activities and communication that make a person a real active subject, distinguishing from the surrounding world.

Identity is closely related to the possibility of human self-development, "self-design", conscious control of the processes of personality development and mental manifestations. In this regard, it is important to understand the dependence of consciousness and self-consciousness of a person on the environment of social life, which affects not only the rate of development of self-consciousness of a particular person, but also the nature of development, determining the typological features of self-consciousness.

Professional self-consciousness is considered in psychology as a part of the general self-consciousness of a person. The process of professional self-consciousness formation is studied as the development of a person's ideas about professional qualities, which are necessary for professional activity.

Problems of professional consciousness and self- consciousness of future lawyers can be solved basing on the category of activity as an indispensable condition that determines personal characteristics, specific manifestations in the professional sphere, productivity of achievements and awareness of cause-and-effect relations at the subjective and objective levels.

The study of professional self-consciousness involves the consideration of issues related to the development of a person as a subject of labor, activities and characteristics of a person as a subject of professional activity.

The principle of unity of consciousness and activity has great importance in the study of the problem of professional self-consciousness development, because activity forms human psyche.

The success of professional activities are affected by developing mental processes, personality features including self-consciousness. Relationships between the person and social world are improving as the result 
of professional activity development. It leads to the formation of professional self-consciousness of the person, which becomes more and more adequate and sufficiently differentiated. Such self-consciousness acts as a factor regulating the implementation of the individual's current activities, as a condition for its development, as well as professional development of the person as a whole. The problem of professional self-consciousness is directly related to the analysis of professional activity, because the individual's own activity (motives, goals, actions, operations, results of activity) becomes the object of reflection.

A. A. Bodalev suggested that "person's profession influences on the perception and understanding of other people. It affects formation of oneself image and understanding of personality" [9]. Bodalev's experiments with actors and engineers have clearly shown the relevance of self-reflection of those characteristics of the Self which are important in the profession.

It can be noted that professionals who have adopted their profession as a way of life acquire a special vision of surrounding world, a special attitude to a number of objects related to the profession and often special perceptual properties that optimize interaction with these objects.

We can assume that employees who have mastered their professional work are characterized by a higher level of professional self-consciousness, which affects the further development of professional skills. Professional skill in any type of activity has a mandatory side - a component in the form of professional selfconsciousness. It is impossible to develop skills without awareness of the professional activity features.

Self-regulation of professional activity is a process of active, purposeful, arbitrary influence of a professional on the performed activities, including setting professional goals, drawing up and correcting action programs that correspond to these goals, evaluating the results of activities. Self-assessment of professional activity is the determination of an individual's ability to perform actual or future activities. An adequate professional selfassessment determines the degree of discrepancy between the level of claims and the real level of performance, the accuracy of setting goals, and an adequate emotional response to various results of activity.

It seems that self-consciousness, understanding and acceptance in the context of social conditions of life and activity are the area of interaction of different personality structures. It is self-consciousness that determines the limits of the possible behavior that a person sets, determining acceptable goals, means, circumstances, results of activity and the degree of expenditure, effort to achieve them, its personal price.

The concept of professionalism is one of the key concepts in the theory of activity. It characterizes the quality indicators, the level achieved in understanding and performing a certain type of activity. In modern psychology, there are several conceptual approaches to the problem of professionalism.

The achievement of professionalism is carried out with an accurate and complete description of the content and structure of activities and individual characteristics. The degree of professional aptitude can be determined by combining these structures.

Currently there is no unified approach to defining the concept of "professional activity" among researchers. Many of them have different interpretations with identical and synonymous approach to some concepts.

If we consider the psychological aspect of the formation of professional behavior and activity, we should talk about the psychological readiness of the person to successful vital activity. In this case, the readiness will be objective and have appropriate objective indicators related to the level of training, professional knowledge, skills. Readiness will have subjective character and will be based on the features of professional consciousness in the form of own subjective relationships and assessments in the field of professional behavior and activity formation.

A certain mental or psychological formation can act as a regulator of the process of realizing the potential of a person in professional activity. It includes a set of individual and typological characteristics that explain the main expression of the personality.

In our opinion professional self- consciousness is an integrative formation that affects professional development. Also it systematically reflects the main characteristics of the individual (such as abilities, orientation, temperament, character) and affects the effectiveness of professional activity.

The activity of lawyers takes place in stressful conditions because of it the search for models of activity must be based on the integrative characteristics of the individual and activity.

Many psychological studies show that the profession affects not only the formation of particular personal characteristics of a professional, but also perception and understanding of the world. Professionals perceive 
the surrounding world and themselves through the prism of the world of their profession.

The professional activity of a lawyer is complex and diverse. It combines a wide variety of challenges and legal regulation of all actions performed with high emotional tension, the organization of own work and communication activities. In condition of socio-economic instability legal activity is significantly more complex. It affects the internal, psychological resources of the individual, which determine the understanding of changes, attitude to them, assessment of the ability to influence them and awareness of the need to adapt activities and behavior adequately to these changes.

The personality of a lawyer is destabilized after graduation. Person comes into dynamics, adapting to changing conditions of activity. Sometimes this process is painless. However most novice lawyers find the strength and opportunities to overcome professional and psychological stress, to achieve positive results for themselves, for law enforcement organizations and for society as a whole.

Legal activity belongs to the group of professions "Person-to-Person", the main object of which is people and their interaction. That is why the interest in a person as a personality with external and internal world is the most important characteristic of such professions.

Thus a comparison of the activities of an investigator, lawyer, judge, prosecutor, forensic expert, police officer, legal adviser other representatives of the legal profession allows us to conclude that despite the generic community of these professions, they all differ significantly in terms of working conditions and requirements for the personality of a professional.

Belonging to the law as a special field of human activity imposes a number of general requirements for specialists of various legal profiles. These requirements are conditioned by the specifics of the subject of the lawyer's work, the features of the means of legal work, and features of the lawyer's activity.

The requirements for training the personality of a person who has chosen the profession of lawyer as the main life goal are increasing because of complexity of various aspects of legal activity. Psychological factors, personal qualities and inclinations are becoming increasingly important at the same time. During the course of studying at a law school such qualities should be brought into the system of skills, abilities and knowledge that ensure the success of practical work. Readiness for legal activity implies a deep consciousness of the social significance of legal work, a developed professional and moral consciousness, the ability to be creative and original in solving professional tasks, the ability to carry out professional communication, etc.

It is necessary to find out what requirements professional legal activity imposes on the specialist before forming an essential characteristic of the lawyer's professional self-consciousness.

The professional activity of lawyers is a type of public service with specific features inherent in this activity. Knowledge of these features is necessary to reflect the professorial work of a lawyer. Also it can be useful for those who seek to get a legal education, master the legal profession and apply their abilities in the field of law enforcement, those who must be ready to overcome the difficulties that they will inevitably meet in their work.

A comprehensive review of the legal profession and the psychological characteristics of the lawyer's work allow seeing the most important areas in this area, to identify ways to improve the effectiveness of the training environment, to evaluate and select people who want to get a legal education and become a lawyer.

It should be noted that the legal regulation of all professional activities distinguishes legal work from other professions and gradually puts an imprint on the lawyer's personality. All the activities of a lawyer, with all its complexity and variety, always take place within the framework of legal regulation. Each lawyer mentally compares future actions with the current legislation regulating these actions.

Communicative activity is one of the main aspects of activity for almost all legal professions. It consists of communication in the conditions of legal regulation. Most legal professions are characterized by high emotional intensity of work. Moreover, this is often associated with negative emotions.

The work of many lawyers is associated with the implementation of special authority powers, with the right and duty to use power in the name of the law.

Another feature of the lawyer's work is the organizational side of the activity, which has two aspects:

a) organization of own work; b) organization of collaborative work with other officials, law enforcement agencies.

A number of the mentioned specific features according to V. L. Vasiliev impose a diverse set of requirements 
on the personality of a lawyer. Success in legal activity is determined by the identification of rational relationships between the individual and the requirements imposed by this profession [13].

A positive attitude to the profession especially at the initial stage of professional activity largely depends on its prestige. Legal profession is one of the most prestigious professions. It is detected by competitions for law schools and other special high schools that train personnel for law enforcement agencies. However many young people choose these professions without having a clear idea of the complexity of the upcoming activities and most importantly they do not know what requirements will be imposed on them.

\section{CONCLUSION}

Young professionals develop skills and techniques for decision-making, skills for analyzing and processing results in the form of documents, stereotypes of business communication with clients during solving legal problems. In short professionally important personal qualities are formed. The adaptation period will be shortened and be less painless for the person if it begins at the university.

The factors and conditions of professionalism can be identified as a result of legal activity analysis. Factors are the main reasons that determine the achievement of high professional performance, which are driving professionalism. Conditions are interpreted as significant circumstances that affect the achievement of high professionalism. Conditions are given greater objectivity at the same time. Factors are given greater subjectivity in relation to a person as a subject of labor. Motives, orientation, abilities, competence, and creativity are considered as subjective factors that determine the measure of professional success. The measure of their expression explains the subjective reasons that promote development of professionalism. The interpretation of these factors from the standpoint of personality theory, activity theory allowed identifying and analyzing more private complex psychological constructs that determine the efficiency of professional consciousness formation of lawyers. It allowed giving structural, functional and conceptual characteristics of professional consciousness also.

Thus the psychological description of the lawyer's activity is based on covering the main provisions of the system approach in the course of studying this category in psychology.

Professional self-consciousness of a lawyer is the main factor that integrates its professionally significant qualities. It is a complex multidimensional hierarchical structure that combines several basic interrelated components: 1) motivational (professional interests and attitudes, the desire to engage in this type of activity); 2) cognitive (professionally necessary knowledge); 3) communicative, which allows using communication with other people in the process of professional activity; 4) affective (internal attitude to professional training and performance).

The problem of developing professionally important qualities of a future lawyer has not received a clear theoretical explanation and has not provided access to practice yet. Modern conditions can be characterized by the instability of the socio-economic surroundings. As usual training and selection of lawyers is based on the assessment of a number of psychological qualities, as well as professional competence, including theoretical and practical training. However these indicators are not an accurate basis for predicting and achieving a high level of professional activity productivity. This problem can be solved by appeal to psychological mechanisms of the individual integration, the most important of which are consciousness and self-consciousness, including professional self-consciousness.

\section{REFERENCE LIST}

Leontiev, A. N. Activity. Consciousness. Personality. - Moscow: Politizdat,1972.

Artemeva, E. Yu. Psychology of subjective semantics. - Moscow, 1980

Halperin, P. Ya. Semantic patterns of behavior underlying higher nervous activity / / Psychology. Vol. 3. Tbilisi, 1945. - Pp. 79-89.

Brushlinsky, A.V. Problems of individual psychology. - Moscow, 1994.

Ananyev, B. G. Man as a subject of knowledge. - L.: Leningrad State University, 1968.

Shorokhova, E. V. Problems of consciousness in philosophy and history. Moscow: Sotsekgiz, 1961.

ISBN: 978-605-82433-9-2 
Proceedings of SOCIOINT 2020- 7th International Conference on Education and Education of Social Sciences, 15-17 June 2020

Leontiev, A. N. Activity. Consciousness. Personality. - Moscow: Politizdat, 1975.

Myasishchev, V. N. Social psychology of relations / Problems of General psychology. Moscow: Nauka, 1965.

Bodalev, A. A. Psychology of communication. - Moscow: MSU Publishing house. UN-TA, 1996. - 256 p. 